Research Article

\title{
Comparison of Elastic Modulus of MWCNT Polyethylene Composites using Nanoindentation and Macromechanical Analysis
}

\author{
P. S. Rama Sreekanth ${ }^{\dot{\mathrm{A}}^{*}}$, Anurag Priyedarshi ${ }^{\dot{\mathrm{B}}}$ and Nitturi Naresh Kumar ${ }^{\dot{\mathrm{C}}}$ \\ ${ }^{\dot{A}}$ Department of Mechanical Engineering, National Institute of Science and Technology, Berhampur, Orrisa \\ ${ }_{\mathrm{B}}^{\mathrm{B}}$ Department of Mechanical Engineering, Indian School of Mines, Dhanbad. \\ ${ }^{\text {C}}$ Plasma Technology Research Center, Department of Physics, Faculty of Science, University of Malay, 50603 Kuala Lumpur, Malaysia
}

Accepted 16 January 2014, Available online 01 February 2014, Special Issue-2, (February 2014)

\begin{abstract}
Ultra high molecular weight polyethylene (UHMWPE) has been in use as an articulating surface in total joint replacements. However, there are critical problems like reduced longevity owing to high activity on the hip joint. In the present study, UHMWPE is reinforced with MWCNTs at different concentration by physical blending using ball milling technique. The samples were obtained using a compression moulding machine, which were used for study under nanoindenter to obtain the elastic modulus. The MWCNTs were randomly oriented and the obtained values of elastic modulus of the composites were compared with that of analytical models like Halpin-Tsai model. The elastic properties of the composites were then analytically estimated for different orientations of carbon nanotubes such as $0 \mathrm{o}, 15 \mathrm{o}$, 30o, $450,600,750$, and 900 at different volume fractions upto $0.5 \%$. Different properties like elastic modulus in $x$ and $y$ direction, Poisson's ratio, in-plane shear modulus and shear coupling coefficients were also calculated and plotted.
\end{abstract}

Keywords: UHMWPE, Carbon nanotubes, nanoindentation, Macromechanical analysis.

\section{Introduction}

UHMWPE is being used as a biomaterial for joint arthroplasty due to its remarkable properties. Ever since its inception, it is being continually evolved through the ages to stand as an immediate alternative for total joint replacements. From the nascent stages of virgin polyethylene to recent developments like surface modification and carbon nanotube composites, UHMWPE has undergone a gradual transition in improving its wear resistance to assist the longevity of implant.

The selection of the reinforcing material used to prepare composite material is based on the requirement of the final product in biomedical application. Several authors have used different filler materials, but there are only a very few articles related to MWCNTs as reinforcements, which are discussed as below. Ruan et al. [2003] reported that the Young's modulus and yield stress of UHMWPE were increased by 38 and $50 \%$, respectively by reinforcing 1 wt. \% MWCNTs. Xue et al. [2006] blended UHMWPE (80 \%) with HDPE (20\%) and the blend was reinforced by MWCNTs $(0.2-2.0$ wt. \%) in order to improve the yield strength and Young's modulus of the blend, which were enhanced by 20 and $26 \%$, respectively at $2 \mathrm{wt}$. \% MWCNTs in the polymer blend. Bakshi et al. [2007] tested UHMWPE/MWCNTs (5 wt. $\%$ ) nanocomposite films prepared by electrostatic spraying technique. The Young's modulus of the composite was

*Corresponding author: P. S. Rama Sreekanth

DOI: http://dx.doi.org/10.14741/ijcet/spl.2.2014.59 increased by $82 \%$. Bakshi et al. [2007a] also evaluated the UHMWPE/MWCNTs nanocomposites using a Nanoindenter, where it was reported that Young's modulus of the nanocomposites were increased by $10 \%$, at 5 wt. $\%$ of MWCNTs in UHMWPE. Morlanes et al. [2011] irradiated 3 wt. \% UHMWPE/MWCNTs composites at $90 \mathrm{kGy}$ in air and it was observed that the Young's modulus, of composites was increased by 34 , whereas the fracture strain was reduced by $44 \%$ compared to that of unirradiated composites. Fonseca et al. [2011] reported that the Young's modulus, strain at fracture and toughness of $0.2 \mathrm{wt}$. \% of MWCNTs in UHMWPE were increased by 80,26 and $35 \%$, respectively. Maksimkin et al. [2012] reinforced UHMWPE with 1 wt. \% MWCNTs and reported that the ultimate strength and yield strength were increased by 286 and $35 \%$, respectively compared to that of virgin UHMWPE.

An attempt is made in the present study to obtain the elastic modulus using nanoindentation technique with analytical models like the Halpin-Tsai. Furthermore, macromechanical analysis has been performed for different orientation of carbon nanotubes with different volume fraction in the UHMWPE matrix. However, the properties for aligned composites were obtained only by analytical models and the experimentation for the same is under consideration.

\section{Materials and methods}

UHMWPE was received from M/s Ticona, Germany,

320 | International Conference on Advances in Mechanical Sciences 2014 
grade GUR 1020 having the molecular weight of $4 \times 10^{6}$ $\mathrm{g} / \mathrm{mol}$ with an average particle size of $140 \pm 20 \mu \mathrm{m}$ and the density of $930 \mathrm{~kg} / \mathrm{m}^{3}$. The MWCNTs were purchased from M/s Shenzhen Nanotech Port Co., Ltd., China. The specifications of as-received MWCNTs are as follows: outer diameter 40-60 nm, length 5- $20 \mu \mathrm{m}$, purity - $95 \mathrm{wt}$. $\%$, ash content $<1.5 \%$, density $-2160 \mathrm{~kg} / \mathrm{m}^{3}$, special surface area $>200 \mathrm{~m}^{2} / \mathrm{g}$. The MWCNTs were chemically treated and then physically blended with UHMWPE in a ball milling machine. The obtained raw material mixture was then consolidated in a compression moulding machine. The details of which were discussed by (Sreekanth et al, 2013). The Nanoindentation experiments were carried out using a CETR, UMT-2 Nanoindenter. The diamond Berkovich tip, which is a 3 -sided pyramid with a total included angle of $136^{\circ}$, was used in this study. The elastic modulus of the composites were calculated using oliver-pharr equations form the reduced stiffness as given in equation 1 , (Briscoe et al, 1998)

$\mathrm{S}=\frac{2 v}{\sqrt{\pi}} \sqrt{\mathrm{A}_{\max }} \mathrm{E}^{*}$

$E^{*}=\left(\frac{1-v_{s}^{2}}{E_{S}}+\frac{1-v_{i}^{2}}{E_{i}}\right)^{-1}$

where $A_{\max }$ is the projection of contact area between the material and indenter tip at $\mathrm{h}_{\max }, v$ is the parameter related to indenter geometry $(1<v<1.034)$ and $\mathrm{E}^{*}$ is the reduced elastic modulus of the contact. E and $v$ with subscripts's' and ' $i$ ' are the elastic moduli and Poisson's ratios of the polymer and the indenter respectively. The obtained elastic modulus was compared with the analytical models of Halpin -Tsai Equations. The governing equation for the Young's modulus of the composites using Halpin-Tsai model is given below in Halpin-Tsai equation

$\frac{E_{C}}{E_{m}}=\frac{3}{8}\left[\frac{1+2\left({ }^{l} / d\right) \eta_{L} V_{c n t}}{1-\eta_{l} V_{c n t}}\right]+\frac{5}{8}\left[\frac{1+2 \eta_{T} V_{c n t}}{1-\eta_{T} V_{c n t}}\right]$

Where $\quad \eta_{T}=\frac{\frac{E_{f}}{E_{m}}-1}{\frac{E_{f}}{E_{m}}+2}, \quad$ and $\eta_{L}=\frac{\frac{E_{f}}{E_{m}}-1}{\frac{E_{f}}{E_{m}}+2(l / d)}$

$E_{C^{-}}$Young's modulus of the composite,

$E_{f}$ Young's modulus of the filler (MWCNT- $1340 \mathrm{GPa}$ ), Belluci [2005]

$E_{m}$ - Young's modulus of the matrix (UHMWPE- 0.617 $\mathrm{GPa})$. (Obtained from the experimental results)

Density of the filler - $2.16 \mathrm{~g} / \mathrm{cc}$ (obtained from manufacturer's data)

Density of the matrix - $0.93 \mathrm{~g} / \mathrm{cc}$ (obtained from manufacturer's data)

(1/d) ratio-86, Kanagaraj et al. [2007]

$\eta_{\mathrm{T}}$ and $\eta_{\mathrm{L}}$ are the parameters depending on the elastic modulus of the matrix and filler materials.

The weight fraction of the composites was converted in to volume fraction considering the density of both matrix and reinforcement, and it is given in the Table 1 .

Table 1 Conversion of weight percentage to volume percentage

\begin{tabular}{|l|l|l|l|l|l|l|}
\hline $\begin{array}{l}\text { MWCNTs } \\
\text { wt. \% }\end{array}$ & 0.5 & 1.0 & 1.5 & 2.0 & 2.5 & 5.0 \\
\hline Vol \% & 0.22 & 0.43 & 0.65 & 0.87 & 1.09 & 2.22 \\
\hline
\end{tabular}

An attempt was also made to find the influence of fiber orientation on the properties of the composites at different filler volume concentration using macro mechanical analysis of composites, (Kaw, 2006). Based on the load acting on the hip joint, the loads acting on the laminate were ascertained to be as follows, $\mathrm{P} 1=2158 \mathrm{~N}$ (tensile), $\mathrm{P} 2=3000 \mathrm{~N}$ (Compressive) and a shear loading of P12 = $1500 \mathrm{~N}$, (Dalstra et al, 1994). The properties of UHMWPE and MWCNTs which were used in the calculation are as given in the Table 2 .

Table 2 Properties of UHMWPE and MWCNTs; (Ticona 2009), (Demczyk et al, 2002)

\begin{tabular}{|l|l|l|l|}
\hline \multicolumn{2}{|l|}{ Properties of UHMWPE (Isotropic) } & \multicolumn{2}{|l|}{ Properties of MWCNT } \\
\hline Young's modulus & $0.617 \mathrm{GPa}$ & $\begin{array}{l}\text { Young's } \\
\text { modulus }\end{array}$ & $940 \mathrm{GPa}$ \\
\hline Shear Modulus & $0.12 \mathrm{GPa}$ & Shear Modulus & $1.7 \mathrm{GPa}$ \\
\hline $\begin{array}{l}\text { Ultimate tensile } \\
\text { strength }\end{array}$ & $28 \mathrm{MPa}$ & $\begin{array}{l}\text { Ultimate tensile } \\
\text { strength }\end{array}$ & $63 \mathrm{GPa}$ \\
\hline Poission's ratio & 0.46 & Poission's ratio & 0.2 \\
\hline $\begin{array}{l}\text { Ultimate compressive } \\
\text { strength }\end{array}$ & $6.8 \mathrm{MPa}$ & $\begin{array}{l}\text { Ultimate } \\
\text { compressive } \\
\text { strength }\end{array}$ & $100 \mathrm{GPa}$ \\
\hline
\end{tabular}

\section{Results and Discussion}

3.1 Comparison of experimentally obtained Young's modulus of randomly oriented fibers with analytical models

The Young's moduli of the composites at different wt. fraction were shown in the Figure 1, where the experimental and analytical results were compared. It is observed that the Young's modulus of UHMWPE was observed to be $0.617 \mathrm{GPa}$, which was increased to 1.67 $\mathrm{GPa}$ at 2 wt. \% of MWCNTs and the corresponding enhancement was about $170 \%$ for ASP samples.

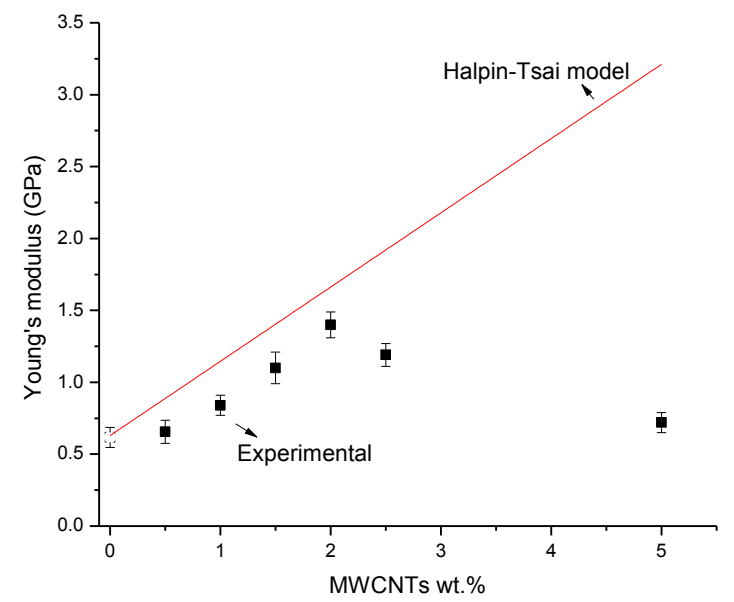

Fig. 1 Comparison of the theoretical and experimental results of the elastic modulus of the composites

When the MWCNTs concentration was further increased to 2.5 and 5 wt. \%, the Young's modulus was observed to be increased by 183.6 and $206.3 \%$, respectively. It is also observed from Figure 1, that the difference between Young's modulus obtained using experimental and HT equations was within $10 \%$ up to 2 wt. \% MWCNTs. 
However, the difference between them is found to increase by 72 and $337 \%$ for 2.5 and 5 wt. \% composites, respectively. The increased difference between them is due to the fact that the theoretical models did not consider the experimental anomalies like the possibility of agglomeration, manufacturing difficulties due to increased filler content, micropores, increased viscosity, difficulties in homogeneous dispersion of reinforcement and others.

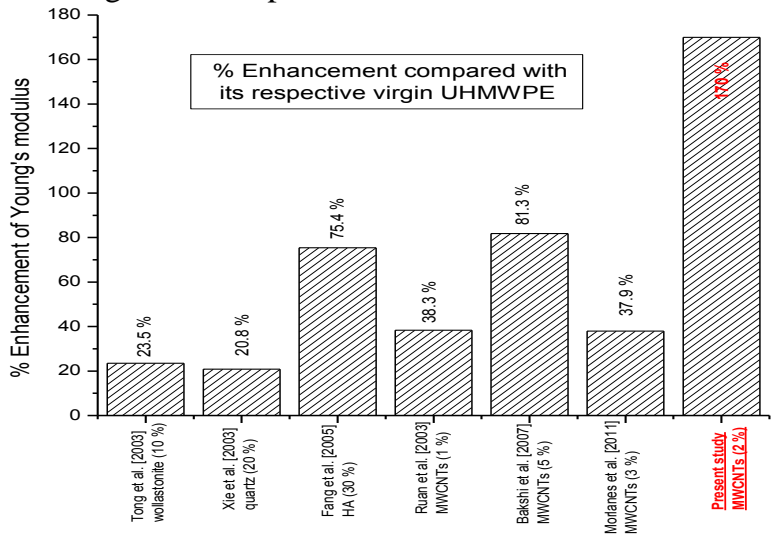

Fig. 2 Comparison of the Young's modulus obtained from the present study with the published literature

It is observed from Figure 2 that the Young's modulus of all the composites with different fillers showed an increasing trend compared to virgin UHMWPE. However, the highest increase of $170 \%$ was obtained in the present study.

\subsection{Estimation of properties of aligned carbon nanotube composites using macro mechanical approach applied to a lamina}

Figure 3 and 4 shows the Young's modulus in X-direction, Y-direction, Poisson's ratio, in-plane shear modulus, shear coupling co-efficient for 0.1 and $0.5 \%$ volume fraction of MWCNTs in UHMWPE
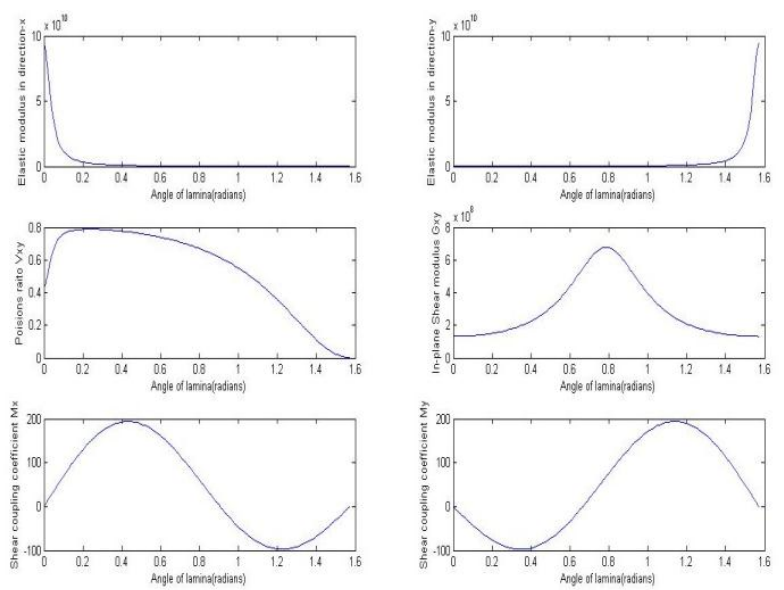

Fig. 3 (a) Elastic modulus in direction-x Vs Angle of lamina (b) Elastic modulus in direction-y Vs Angle of lamina (c) Poisson's Ratio Vs Angle of lamina (d) Inplane shear modulus Vs Angle of lamina (e) Shear Coupling Coefficient MxVs Angle of lamina (f) Shear Coupling Coefficient MyVs Angle of lamina for $0.1 \mathrm{v} \%$ MWCNT (Fig a,b,c,d,e,f left to right)
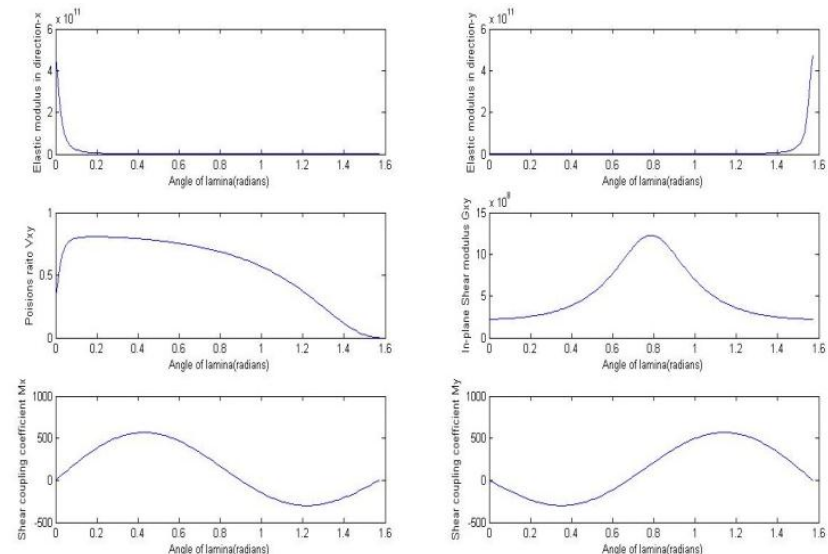

Fig. 4 (a) Elastic modulus in direction-x Vs Angle of lamina (b) Elastic modulus in direction-y Vs Angle of lamina (c) Poisson's Ratio Vs Angle of lamina (d) Inplane shear modulus Vs Angle of lamina (e) Shear Coupling Coefficient MxVs Angle of lamina (f) Shear Coupling Coefficient MyVs Angle of lamina for $0.5 \mathrm{v} \%$ MWCNT. (Fig a,b,c,d,e,f left to right)

Table3 Properties for $45^{\circ}$ orientated MWCNTs in polyethylene

\begin{tabular}{|l|l|l|l|l|l|l|}
\hline $\begin{array}{l}\text { Volume Fraction } \\
\text { Properties }\end{array}$ & $\begin{array}{l}\text { Multip } \\
\text { le of }\end{array}$ & $\mathbf{0 . 1}$ & $\mathbf{0 . 2}$ & $\mathbf{0 . 3}$ & $\mathbf{0 . 4}$ & $\mathbf{0 . 5}$ \\
\hline Elastic Modulus Ex & $10^{8}$ & 4.43 & 4.94 & 5.59 & 6.44 & 7.5 \\
\hline Elastic Modulus Ey & $10^{8}$ & 4.43 & 4.94 & 5.59 & 6.44 & 7.5 \\
\hline Poisson's ratio & & 0.67 & 0.67 & 0.68 & 0.68 & 0.69 \\
\hline $\begin{array}{l}\text { Shear Coupling } \\
\text { coefficient Mx }\end{array}$ & & 68.46 & $\begin{array}{l}121 . \\
7\end{array}$ & $\begin{array}{l}159.7 \\
5\end{array}$ & 182.58 & 190.1 \\
\hline $\begin{array}{l}\text { Shear Coupling } \\
\text { coefficient My }\end{array}$ & & 68.46 & $\begin{array}{l}121 . \\
7\end{array}$ & $\begin{array}{l}159.7 \\
5\end{array}$ & 182.58 & 190.1 \\
\hline Gxy & $10^{8}$ & 6.76 & 7.65 & 8.76 & 10.23 & 12.2 \\
\hline
\end{tabular}

Table 4 Properties for $60^{\circ}$ orientated MWCNTs in polyethylene:

\begin{tabular}{|l|l|l|l|l|l|l|}
\hline $\begin{array}{l}\text { Volume } \\
\text { Fraction } \\
\text { Properties }\end{array}$ & $\begin{array}{l}\text { Multipl } \\
\text { e of }\end{array}$ & $\mathbf{0 . 1}$ & $\mathbf{0 . 2}$ & $\mathbf{0 . 3}$ & $\mathbf{0 . 4}$ & $\mathbf{0 . 5}$ \\
\hline $\begin{array}{l}\text { Elastic Modulus } \\
\text { Ex }\end{array}$ & $10^{8}$ & 4.47 & 4.99 & 5.66 & 6.54 & 7.73 \\
\hline $\begin{array}{l}\text { Elastic Modulus } \\
\text { Ey }\end{array}$ & $10^{8}$ & 6.61 & 7.37 & 8.33 & 9.58 & 11.26 \\
\hline Poisson's ratio & & 0.51 & 0.51 & 0.51 & 0.52 & 0.52 \\
\hline $\begin{array}{l}\text { Shear Coupling } \\
\text { coefficient Mx }\end{array}$ & -65.1 & -118.1 & -159.35 & $\begin{array}{l}- \\
188.8\end{array}$ & -206 \\
\hline $\begin{array}{l}\text { Shear Coupling } \\
\text { coefficient My }\end{array}$ & & 183 & 328.9 & 436.06 & $\begin{array}{l}505.0 \\
7\end{array}$ & 535 \\
\hline Gxy & $10^{8}$ & 3.33 & 3.73 & 4.24 & 4.89 & 5.79 \\
\hline
\end{tabular}

Table 3 shows the properties of composites for a $45^{\circ}$ orientation of MWCNTs in polyethylene, while Table 4 shows the same for a $60^{\circ}$ oriented MWCNTs lamina.

It is observed from Figure $3 \mathrm{a}$ that Elastic modulus of 0.1 wt. \% composites decreases in direction-x sharply for small increment in angle of orientation of filler, and thereafter fairly remained constant. The elastic modulus was reduced from $94.5 \mathrm{GPa}$ to $2.05,0.66,0.443 \mathrm{GPa}$ as the orientation angle of MWCNTs increased from $0^{\circ}$ to 
$15^{\circ}, 30^{\circ}$, and $45^{\circ}$, respectively. Thereafter the elastic modulus slightly increased to $0.447,0.574$ and $0.685 \mathrm{GPa}$ with increase in orientation angle to $60^{\circ}, 75^{\circ}$ and $90^{\circ}$. The elastic modulus in direction-y, as shown in Figure $3 \mathrm{~b}$, increased from $0.685 \mathrm{GPa}$ to $94.5 \mathrm{GPa}$ as the orientation angle increased from 0 to $90^{\circ}$, i.e., an exactly opposite trend compared to that of $\mathrm{E}_{\mathrm{x}}$.

The Poisson's ratio of the composites shown in Figure $3 \mathrm{c}$, increased with orientation upto $15^{\circ}$ and thereafter reduced continuoulsy. The Poisson's ratio for $0,15,30$, $45,60,75$, and 90 degree orientation of MWCNTs in UHMWPE were found to be $0.434,0.788,0.756,0.676$, $0.511,0.220$ and 0.03 , respectively. That is the Poisson's ratio was found to be maximum for $15^{\circ}$ orientation of filler and then decreased continuously with a further increase in angle of orientation. The in-plane shear modulus of the composites is shown in Figure 3d, where a Hill-shaped curve is observed. Magnitude of Gxy increased with an increase in orientation angle of the filler upto $45^{\circ}$ and reduced thereafter. The maximum value of shear modulus occurred at $45^{\circ}$ orientation. The shear coupling coefficients Mx and My are shown in Figure 3e and 3f. It is observed that the trend exhibited a sinusoidal curve in either case. However, the trend of $\mathrm{Mx}$ and $\mathrm{My}$ were opposed to each other. The maximum value of Mx occurs at $30^{\circ}$ and minimum at $60^{\circ}$, while for My the maximum value occurred at $60^{\circ}$ and the minimum was observed at $30^{0}$.

The mechanical properties for $0.5 \mathrm{v} \%$ of MWCNTs reinforcement are shown in Figure 4a-f. The elastic modulus in $\mathrm{x}$ - direction reduced from 470 to $1.23 \mathrm{GPa}$ as the orientation changed from 0 to $90^{\circ}$. The elastic modulus Ey, shown in Figure 4b, reduced with increase in orientation angle. It was observed to be $1.23,1.01$, $0.77,0.75,1.12,0.35,0.47 \mathrm{GPa}$, respectively for $0,15,30$, $45,60,75$ and $90^{\circ}$ orientation of filler in UHMWPE. The Poisson's ratio was increased from 0.33 for $0^{\circ}$ to 0.80 for $15^{\circ}$ orientation and thereafter it has continuously reduced with further increase in the angle of orientation of the filler. The in plane shear modulus, as shown in Figure 4d, increased form 0.22 to $1.22 \mathrm{GPa}$ as the orientation angle increased from 0 to $45^{\circ}$. There after the shear modulus reduced with angle of orientation and it was observed to be $0.224 \mathrm{GPa}$ at $90^{\circ}$. The shear coupling coefficients $\mathrm{Mx}$ and My has shown opposed trends similar to that exhibited in $0.1 \%$ composite. In general the trend exhibited by all the mechanical properties remained the same at different volume fractions of MWCNTs in UHMWPE, however, with a variation in their magnitude.

Table 3 and 4 shows the mechanical properties of composites for 45 and $60^{\circ}$ orientation at different volume fraction of MWCNTs. It is observed from Table 3 that the elastic modulus Ex and Ey remained the same in at all the volume fractions of MWCNTs. Similarly, the shear coupling co-efficients MX and My were also identical at all concentration of filler. The poisson's ratio remained fairly constant, while the shear modulus increased with the filler concentration. Table 4 shows the properties for a $60^{\circ}$ oriented filler. It is observed that the elastic modulus Ex increased 0.44 to $0.73 \mathrm{GPa}$ and Ey increased form 0.66 to 1.1 GPa as the concentration of MWCNTs increased form
0.1 to $0.5 \mathrm{v} \%$. In general all the mechanical properties increased with the increase in volume fraction of MWCNTs. However, it is to be noted that, these analytical results may considerably differ from the experimental values at higher concentrations of MWCNTs in UHMWPE. This can possibly happen due to anomalies like increased viscosity, agglomeration and other manufacturing difficulties, which were discussed earlier. The experimental work for aligned MWCNTs composites is under progress.

\section{Conclusions}

The elastic modulus of the developed composites has been found using nanoindentation technique and the results were compared with that of analytical models. The other laminate properties for aligned composites have been estimated using the macromechanical approach of composites, however, the experimental work of the same is under progress. The following are the conclusions from the present work.

1) The Young's modulus of composites increased with MWCNT concentration.

2) The difference between the analytical and experimental results for elastic modulus increased with MWCNTs concentration, this is primarily due to the fact that the theoretical models did not consider the experimental anomalies like the possibility of agglomeration, manufacturing difficulties.

3) The mechanical properties of aligned CNT composites were superior compared to randomly oriented composites.

4) As the volume fraction of filler increased, the mechanical properties like Elastic modulus in direction- $x$, and in direction-y increased in magnitude.

5) While properties like Poisson's Ratio, Shear coupling coefficient $\mathrm{Mx}$ and $\mathrm{My}$ increased first then after attaining maximum value it decreases with an increase in angle of orientation of filler for a given volume fraction.

\section{Acknowledgements}

Authors acknowledge the experimental support received form central instruments facility, Indian Institute of technology, Guwahati.

\section{References}

A.K.Kaw, (2006) Mechanics of Composite Materials, CRC Press, Taylor \& Francis, New york.

S.R. Bakshi, J.E. Tercero, A. Agarwal, (2007), Synthesis and characterization of multiwalled carbon nanotube reinforced ultra high molecular weight polyethylene composite by electrostatic spraying technique, Composites: Part A, 38:2493-2499.

S.R. Bakshi, K. Balani, T. Laha, J. Tercero, A. Agarwal, (2007a), The nanomechanical and nanoscratch properties of MWNT reinforced ultrahigh-molecular weight polyethylene coatings, Journal of the Minerals, Metals and Materials Society, 59,5053. 
B.J. Briscoe, L. Fiori, E. Pelillo, (1998), Nanoindentation of polymeric surfaces. Journal of Physics. D: Applied Physics, 31, 2395-2405.

A. Fonseca, S. Kanagaraj, M.S.A. Oliveira, J.A.O. Simões, 2011 Enhanced UHMWPE reinforced with MWCNT through mechanical ball-milling, Defect and Diffusion Forum, 312315,1238-1243

A.V. Maksimkin, S.D. Kaloshkin, M.S. Kaloshkin, M.V. Gorshenkov, V.V. Tcherdyntsev, K.S. Ergin, I.V. Shchetinin, (2012), Ultra-high molecular weight polyethylene reinforced with multi-walled carbon nanotubes: Fabrication method and properties. Journal of Alloys and Compounds, 2012, 536: 538540.

M.J.M. Morlanes, P. Castell, V.M. Nogués, M.T. Martinez, P.J. Alonso, J.A. Puértolas, (2011), Effects of gamma-irradiation on UHMWPE/MWNT nanocomposites, Composite Science Technology, 71,282-288.
P. S. Rama Sreekanth, S. Kanagaraj, (2013) Assessment of Surface and Bulk Properties of UHMWPE/MWCNT Nanocomposites using Nanoindentation and Microtensile Testing, Journal of Mechanical Behavior of Biomedical Materials 18, 140-151,.

S.L. Ruan, P. Gao, X.G. Yang, T.X. Yu, (2003), Toughening high performance ultrahigh molecular weight polyethylene using multiwalled carbon nanotubes, Polymer, 44, 5643-5654.

Y. Xue, W. Wu, O. Jacobs, B. Schadel, (2006) Tribological behaviour of UHMWPE/HDPE blends reinforced with multiwall carbon nanotubes, Polymer Testing, 25,221-229.

S.Belluci, (2005). Carbon nanotubes: Physics and applications, Physica Status Solidi C, 2 (1), 34-47.

B.G.Demczyk, Y.M Wang, J. Cumings, M. Hetman, W. Han, A. Zettl, R.O. Ritchie, (2002), Direct mechanical measurement of the tensile strength and elastic modulus of multiwalled carbon nanotubes, Materials Science and Engineering A, 334 (1-2) 173-178. 